\title{
ASO Author Reflections: Safety of Abdominal Surgical Cytoreduction Combined with Locoregional Chemohyperthermia
}

\author{
Pompiliu Piso, MD, PhD \\ Department of General and Visceral Surgery, Hospital Barmherzige Brüder, Regensburg, Germany
}

\section{PAST}

Cytoreductive surgery (CRS) and hyperthermic intraperitoneal chemotherapy (HIPEC) have been recommended in several guidelines for the treatment of selected patients with peritoneal surface malignancies. As this is an aggressive strategy, many medical practitioners are concerned about the associated high mortality and morbidity figures, particularly if performed nationwide and not only in highly specialized centers. ${ }^{1}$ To investigate this, we performed a retrospective analysis of prospective documented data from a large national registry, with a focus on morbidity and mortality following CRS and HIPEC.

\section{PRESENT}

For the first time, data from the German HIPEC Registry are reported, demonstrating that the concept of CRS and HIPEC is safe and can be performed with a low mortality. ${ }^{2}$ Coming from a large national registry of more than 50 institutions, these data have a high relevance for the clinical routine practice of clinical oncologists. Moreover, the presented results show that CRS and HIPEC can be safely performed nationwide if close mentoring by experienced centers is provided. ${ }^{3}$

ASO Author Reflections is a brief invited commentary on the article "Morbidity and Mortality Following Cytoreductive Surgery and Hyperthermic Intraperitoneal Chemotherapy: Data From the DGAV Studoq Registry with 2149 Consecutive Patients", Ann Surg Oncol. Epub 19 Nov 2018. https://doi.org/10.1245/s10434-018-6992-6.

(C) Society of Surgical Oncology 2018

First Received: 15 November 2018;

Published Online: 26 November 2018

P. Piso, $\mathrm{MD}, \mathrm{PhD}$

e-mail: pompiliu.piso@barmherzige-regensburg.de

\section{FUTURE}

Registry data are associated with some bias, particularly in relation to missing data. ${ }^{4}$ Therefore, data completion must become mandatory and must be reduced to essential parameters. The complete entered data must be verified by the quality manager of every involved center and should be part of a certification process, with an audit performed by a third-party auditor. The mentoring process is effective for new centers treating patients with CRS and HIPEC; however, for re-do procedures, recurrences, and high-risk patients, treatment in high-volume centers is recommended.

DISCLOSURES Pompiliu Piso has no conflicts of interest to disclose.

\section{REFERENCES}

1. Chua TC, Yan TD, Saxena A, et al. Should the treatment of peritoneal carcinomatosis by cytoreductive surgery and hyperthermic intraperitoneal chemotherapy still be regarded as a highly morbid procedure? A systematic review of morbidity and mortality. Ann Surg. 2009;249:900-7.

2. Piso P, Nedelcut DS, Rau B, et al. Morbidity and mortality following cytoreductive surgery and hyperthermic intraperitoneal chemotherapy: data from the DGAV StuDoQ registry with 2149 consecutive patients. Ann Surg Oncol. Epub 19 Nov 2018. https://d oi.org/10.1245/s10434-018-6992-6.

3. Mohamed F, Moran BJ. Morbidity and mortality with cytoreductive surgery and intraperitoneal chemotherapy: the importance of a learning curve. Cancer J. 2009;15(3):196-9.

4. Parsons HM, Henderson WG, Ziegenfuss JY, et al. Missing data and interpretation of cancer surgery outcomes at the American College of Surgeons national surgical quality improvement program. J Am Coll Surg. 2011;213:379-91. 